\title{
Levana Bacteriana: aspectos tecnológicos, características e produção
}

\section{Bacterial Levan: tecnological aspects, characteristics and production}

\author{
Fernanda M. P. G. Ernandes ${ }^{1 *}$; Crispin Humberto Garcia-Cruz ${ }^{2 *}$
}

\begin{abstract}
Resumo
Levana é um exopolissacarídeo, constituído por unidades de frutose, unidas através de ligações $\beta$ (2- 6), obtido pela reação de transfrutosilação durante a fermentação de microrganismos em meio rico em sacarose mas não em frutose, glucose ou misturas de ambas. Pesquisas sobre bactérias produtoras de levana vêm sendo implementadas, uma vez que a mesma é uma fonte alternativa de frutose, além de apresentar características funcionais no organismo humano, como agente hipocolesterolêmico e anticarcinogênico. Na indústria de alimentos a levana pode ser empregada como fixador de cores e sabores, bem como espessante e estabilizante de vários alimentos. Das bactérias produtoras de levana, Zymomonas mobilis tem sido a melhor alternativa, uma vez que usa como fonte de carbono a sacarose ou resíduos industriais contendo este açúcar, em diferentes concentrações, em um meio rico em sais minerais. A produção de levana é influenciada não apenas pela fonte de carbono e sua concentração, mas também pelas variações de $\mathrm{pH}$, temperatura e tipo de sais presentes, além da oxigenação do meio de fermentação, afetando também as características da molécula e o crescimento celular. Neste trabalho de revisão apresentam-se tópicos de interesse referentes à produção de levana bacteriana.
\end{abstract}

Palavras-chave: Levana, produção, características tecnológicas, bactérias

\begin{abstract}
Levan is an exopolysaccharide, constituted by fructose units, $\beta$ (2-6) linked, obtained by transfructosilation reaction during microorganisms fermentation in a sucrose rich but wi thout glucose, fructose or mixtures in the culture media. Bacterial levan production is a good alternative fructose source, besides having certain functional characteristics in the human body, such as a hypocholesterolemic and an anticarcinogenic agent. In the food industry, levan can be used to fix colors and flavors, as well as thickening and stabilizing agent. In the bacterial levan production, Zymomonas mobilis has been considered the best possible alternative, since it uses as carbon source sucrose or industrial residues that contain this sugar, in different concentrations, in a mineral salts rich medium. Levan production is not only influenced by carbon source and its concentration, but also by $\mathrm{pH}$, temperature and type of salts. Moreover, the oxygenation of the fermentation medium, also affect the characteristics of the molecule and the cellular growth. In this revision some important topics concerning the bacterial levan production are presented.
\end{abstract}

Key words: Levan, production, technological characteristics, bacteria

\footnotetext{
1 Departamento de Engenharia e Tecnologia de Alimentos - Instituto de Biociências, Letras e Ciências Exatas - UNESP Campus de São José do Rio Preto, SP. E-mail fernandaer@ig.com.br

2 Departamento de Engenharia e Tecnologia de Alimentos - Instituto de Biociências, Letras e Ciências Exatas - UNESP Campus de São José do Rio Preto, SP. E-mail crispin@eta.ibilce.unesp.br

* Autor para correspondência
} 


\section{Introdução}

A indústria alimentícia torna-se cada vez mais dependente da produção de alimentos altamente processados, ao invés de simplesmente preservar as matérias-primas obtidas no campo. Muito desse desenvolvimento, porém, tem sido resultado da criatividade ou manipulação empírica, muitas vezes por tentativa e erro, de ingredientes sobre os quais se tem pouco conhecimento científico. Dentre estes, destaca-se uma classe de polissacarídeos denominados hidrocolóides - ou gomas, como são comumente conhecidos - cuja característica mais importante, sob o ponto de vista tecnológico, é sua capacidade de determinar ou modificar a estrutura de um alimento.

Esses polissacarídeos possuem uma ampla gama de propriedades funcionais, atuando como estabilizantes, espessantes, gelificantes e crioprotetores, sendo muitas vezes os principais responsáveis pela textura (corpo, viscosidade e consistência) dos alimentos processados.

Os hidrocolóides podem ser de origem vegetal, marinha ou microbiana. As gomas de origem vegetal são obtidas de exsudados de árvores (gomas arábica e karaya), de sementes (gomas guar e locusta) e de frutas cítricas (pectina), enquanto as de origem marinha são obtidas de algas (alginato, ágar e carragena), e as de origem microbiana são obtidas por fermentação de substratos ricos em nutrientes (xantana, curdlana e levana).

Os polissacarídeos de origem microbiana, chamados biopolímeros, apresentam algumas vantagens para sua obtenção em relação às outras gomas, tais como: não dependência das condições climáticas, possibilidade de utilização de matériasprimas regionais, maior rapidez na obtenção do produto acabado e necessidade de menor espaço físico das instalações fabris. Além disso, as gomas de origem microbiana apresentam maior uniformidade em suas propriedades físico-químicas, devido à especificidade do microrganismo utilizado e à possibilidade de um rígido controle dos parâmetros de fermentação, como $\mathrm{pH}$, temperatura, taxa de aeração, velocidade de agitação, tempo de fermentação e composição do meio de cultura.

Os exopolissacarídeos como a xantana vêm sendo utilizados há muitos anos pela indústria de alimentos devido às suas propriedades espessantes e estabilizantes. A dextrana é utilizada na indústria farmacêutica como fonte de glicose. Alguns outros, como a gelana, são gelificantes; a celulose bacteriana é usada para produção de biofilmes (pele sintética) e o ácido hialurônico em cosméticos. Apesar de todos estes apresentarem propriedades funcionais atrativas, a pesquisa por novos polissacarídeos bacterianos continua a ser realizada. Destes a levana $(\beta$-Dfrutana) tem-se destacado como uma boa fonte de frutose. Suas propriedades apresentam excelente expectativa na área da saúde, por possuírem potencialidade terapêutica aproveitável na área farmacológica, por exemplo, como substituto de plasma sanguíneo, imunomodulador, anticarcinogênico e hipocolesterolêmico.

A levana é formada através de reações de transfrutosilação e é constituída, basicamente, de unidades de frutose ligadas em $\beta$ (2 6). Pode ser sintetizada por vários grupos de bactérias, entre elas a Zymomonas mobilis, em um meio fermentativo à base de sacarose, extrato de levedura e sais minerais.

$\mathrm{Na}$ indústria de alimentos a levana pode ser empregada como fixador de cores e sabores, espessante e estabilizante em géis para sobremesas, em temperos prontos para salada, em pudins, sorvetes e derivados do leite, em bebidas, coberturas para produtos de confeitaria e ainda como invólucro de embutidos. Nos alimentos funcionais, também conhecidos como produtos probióticos, a levana representa um eficiente aditivo que pode influenciar de modo benéfico o funcionamento do trato intestinal e, conseqüentemente, o balanço nutricional do organismo humano.

Portanto, o potencial de aplicações deste polímero nos setores alimentício e farmacêutico está promovendo uma intensa e constante pesquisa 
visando entender melhor as vias metabólicas de síntese, a função fisiológica, a biologia dos microrganismos produtores e, com isto, regular sua formação e composição, e ainda a otimização do processo de produção.

\section{Revisão Bibliográfica}

\section{Considerações Gerais}

As bactérias e os fungos são responsáveis por importantes transformações metabólicas, controle biológico de doenças e pragas, fixação biológica do nitrogênio atmosférico, degradação de resíduos vegetais e, inclusive, produtores de substâncias tóxicas. Produzem, também, um manancial de compostos que podem ser utilizados como fármacos, corantes, enzimas, ácidos orgânicos e polissacarídeos, além de muitos derivados úteis conhecidos, mas ainda inexplorados (MELO; AZEVEDO, 1998).

A aplicação dos biopolímeros em produtos alimentícios é muito vasta devido às suas propriedades e características específicas, tais como: aumento da viscosidade mesmo quando usados em baixas concentrações, estáveis em relação ao calor resistindo a altas temperaturas durante o processamento, excelente solubilidade e estabilidade em meio ácido e na presença de sais (principalmente cloreto de sódio), eficientes como estabilizadores de emulsões evitando a separação da gordura nos sistemas óleo/ água, natureza altamente pseudoplástica diminuindo o arraste durante o escoamento, tudo isso somado às vantagens de produção alheia às condições climáticas, uma vez que podem ser obtidos sob condições controladas (SUTHERLAND, 1999).

Entre os biopolímeros mais utilizados, a goma xantana (Figura 1) produzida pela linhagem de Xanthomonas campestris tem sido a mais estudada, uma vez que seu uso em alimentos foi permitido pelo Food and Drug Administration (FDA) desde julho de 1969. Representa $90 \%$ do volume total de vendas dos polímeros bacterianos devido às suas extraordinárias propriedades reológicas, que são bem exploradas nas indústrias de alimentos, têxtil e na recuperação de óleos (TAKO; NAKAMURA, 1987).

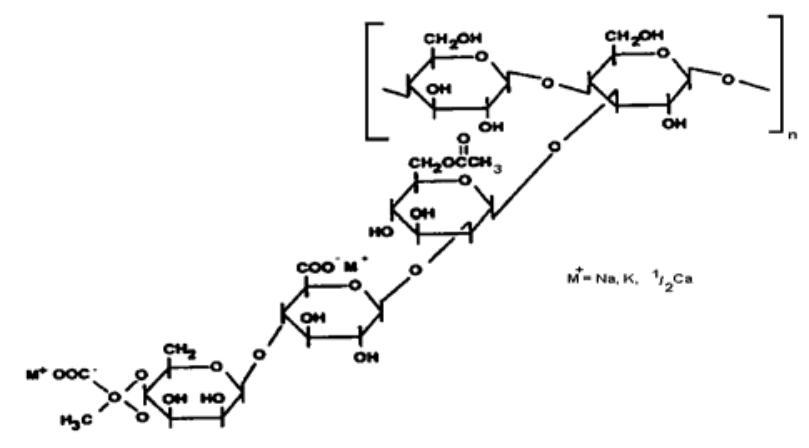

Figura 1. Estrutura da goma xantana

A goma gelana (Figura 2) foi o segundo biopolímero de origem microbiana a ser aprovado para uso em alimentos pelo FDA, em 1992. Sua descoberta deu-se em 1977, quando a bactéria produtora Pseudomonas elodea foi identificada pela primeira vez durante uma pesquisa sobre microrganismos sintetizadores de gomas isolados do ambiente. Passou a ser comercializada pela Kelco Co. (EUA) e vem sendo apontada como um dos mais eficientes e multifuncionais hidrocolóides desenvolvidos até o momento (PSZCZOLA, 1993).

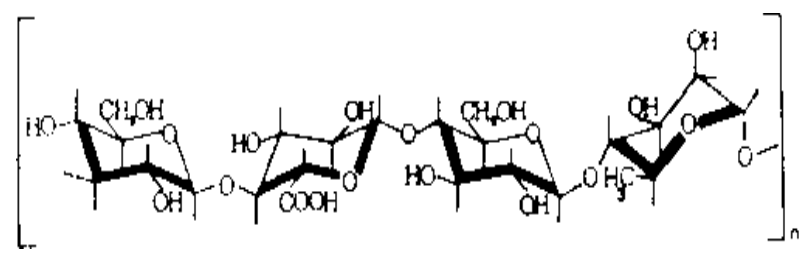

Figura 2. Estrutura da goma gelana

Além desses polissacarídeos, a levana tem despertado grande interesse devido às suas aplicações em diversas áreas como saúde e alimentação humana.

O termo "levana" (Figura 3) refere-se a um exopolissacarídeo obtido pela reação de transfrutosilação durante a fermentação de culturas crescidas em meios ricos em sacarose. Segundo 
Swings e Deley (1977), a levana é produzida a partir da sacarose e não da glicose, frutose ou misturas de ambas. Sendo um anidrofructosilfructosídeo solúvel em água, a levana pode também ser chamada de polifrutana pelo fato de ser constituída de moléculas de frutose (GARCIA-CRUZ, 1997).

A levana possui massa molecular de aproximadamente $10^{7}$ Daltons, correspondente a aproximadamente 60.000 unidades de frutose unidas por ligações $\beta$ (2 6). Os polímeros de levana são lineares ou ramificados (graus variáveis) na hidroxila do carbono 1 (MURO et al., 2000).

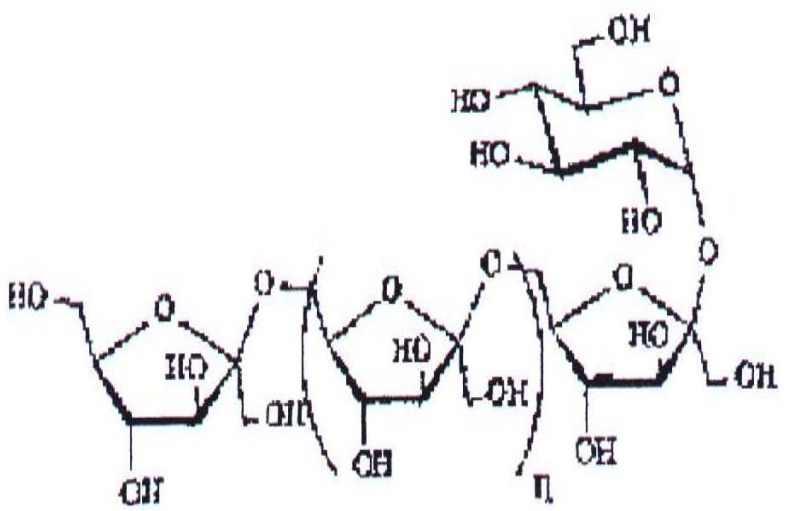

Figura 3. Estrutura $\beta$ (2 6) da ramificação principal da levana

A levana é facilmente produzida por diferentes tipos de bactérias durante a assimilação de sacarose (CHA et al., 2001) em meios inoculados com Zymomonas mobilis (REISS; HARTMEIER, 1990; BEKERS et al., 2000). Entretanto, outros grupos de microrganismos estudados por vários pesquisadores também são produtores de levana conforme especificados na Tabela 1.
Tabela 1. Microrganismos produtores de levana

\begin{tabular}{c|c} 
MICRORGANISMOS & PESQUISADORES \\
'RODUTORES DE LEVANA & \\
\hline Acetobacter suboxydans & Tkachenko; Sevryugina (1989) \\
$\begin{array}{c}\text { Aerobacter levanicum } \\
\text { Erwinia herbicola } \\
\text { Streptococcus salivarius } \\
\text { Bacillus mesentericus } \\
\text { Bacillus subtilis } \\
\text { Bacillus polymyxa }\end{array}$ & Gunasekaran, Raj (1999) \\
Pseudomonas syringae & Gandhi; Ray; Patel (1997) \\
& Han (1989); Han; Watson (1992) \\
& Hettwer; Gross; Rudolph (1995) \\
\hline
\end{tabular}

Os microrganismos produtores de levana também produzem fructooligossacarídeos (FOS) que possuem várias funções fisiológicas (CHA et al., 2001). Estes oligossacarídeos não são hidrolisados pelas enzimas digestivas e então, são usados em alimentação de pessoas com diabetes e inibem o desenvolvimento de microrganismos potencialmente patogênicos (YUN, 1996).

Segundo Leibovici et al. (1979), é possível o uso de levana em medicina como um componente funcional dotado de atividade biológica para o funcionamento adequado do organismo humano. A literatura relata usos práticos de levana para vários propósitos, por exemplo, como complexo biologicamente ativo, substituto de plasma sanguíneo, agente prolongador da ação de fármacos, preparação de frutose altamente purificada para uso médico (MAYS; DALLY, 1988), fator de promoção do crescimento de Bifidus spp (UEDA et al., 1994; TAPER; DELZENNE; ROBERFROID, 1997), agente hipocolesterolêmico (YAMAMOTO et al., 1999) e como imunomodulador e anticarcinogênico (LEIBOVICI; STARK, 1985; LOPES; ANDRADE; MANO, 1991; CALAZANS et al., 1997; VINA et al., 1997). 
$\mathrm{Na}$ indústria de alimentos, a levana tem vários usos potenciais: agente espessante, fixador de cores e sabores e em produtos dietéticos (YUN, 1996). Além disso, sua hidrólise produz frutose que tem poder adoçante superior à sacarose.

Como mencionado por Pace e Righelato (1980) o alto custo de produção dos polissacarídeos xantana e dextrana estimulou novas pesquisas por outros polissacarídeos microbianos. O interesse comercial pela levana motiva pesquisas tanto para a identificação de novos microrganismos produtores quanto para processos que visem à otimização de sua produção em escala industrial (REISS; HARTMEIER, 1990; KEITH et al., 1991; HARTMEIER et al., 1994; TANO; BUZATO, 2003).

\section{Produção de Polissacarídeos}

De acordo com Sutherland (1972), os biopolímeros sintetizados por bactérias são divididos, segundo sua localização, em três grupos: (1) polissacarídeos intracelulares (armazenam diferentes formas de carbono); (2) polissacarídeos integrantes da parede celular (peptidoglicanos e ácidos teicóicos) e, (3) polissacarídeos extracelulares (formam cápsulas e estão associados à superfície celular ou são secretados no meio de cultura).

Além da localização, os polissacarídeos extracelulares podem ser classificados em homo ou heteropolissacarídeos. Os homopolissacarídeos, como por exemplo, dextrana e levana, são constituídos por somente um tipo de açúcar e são geralmente produzidos por uma só enzima ou por um sistema simples de enzimas. Devido a essa simplicidade do sistema, estes polissacarídeos podem ser produzidos em sistemas livres de células, ou seja, por síntese enzimática. Em contraste, os heteropolissacarídeos são constituídos por vários tipos de açúcares e sintetizados por sistemas enzimáticos complexos (SANDFORD, 1982; SUTHERLAND, 2001).

O efeito das condições para produção de polissacarídeos extracelulares por espécies microbianas tem sido estudado tanto para culturas em crescimento como para células em suspensão. Também têm sido pesquisadas as limitações das fontes de nitrogênio, fosfato ou enxofre em presença de diferentes concentrações de carboidratos. Observou-se que podem conduzir a um aumento na síntese de polissacarídeo, embora a quantidade seja também afetada pelo teor de oxigênio, $\mathrm{pH}$ e temperatura, além do que, cada linhagem difere em sua resposta ao efeito das mudanças ambientais e à utilização da fonte de carbono. As condições ideais para o crescimento e a produção de polissacarídeo em culturas descontínuas também são afetadas pela proporção entre o volume de ar e o volume de meio, presença ou ausência de agitação, quantidade do inóculo, além dos nutrientes que fazem parte do meio de cultura (SUTHERLAND, 1993; GARCIACRUZ, 1997; BUENO, 2001; BUENO; GARCIACRUZ, 2001; QUEIROZ, 2001; FARIA, 2002; COLTRO, 2003).

Como regra geral, devem-se fornecer nutrientes necessários para o crescimento e produção de biopolímero. Para isto, o meio deve conter algum tipo de carboidrato, sais de amônio ou aminoácidos e vários sais inorgânicos que atuam como fonte de íons e também como cofatores enzimáticos na síntese do polissacarídeo. Alguns microrganismos necessitam, ainda, de vitaminas e antibióticos (SUTHERLAND, 1993; SANDFORD; COTTRELL; PETTITT, 1984).

Os nutrientes inorgânicos comumente necessários para o crescimento podem ser divididos em macronutrientes, tais como fósforo $\left(\mathrm{KH}_{2} \mathrm{PO}_{4}\right)$; potássio $(\mathrm{KCl})$; magnésio $\left(\mathrm{MgCl}_{2} \cdot 6 \mathrm{H}_{2} \mathrm{O}\right.$ ou $\left.\mathrm{MgSO}_{4}\right)$; cálcio $\left(\mathrm{CaCl}_{2}\right)$; sódio $\left(\mathrm{NaCl}\right.$ ou $\left.\mathrm{Na}_{2} \mathrm{CO}_{3} \cdot 3 \mathrm{H}_{2} \mathrm{O}\right)$ que podem ser utilizados entre 0,001 a 4,0 g por $100 \mathrm{~mL}$ eiras; em micronutrientes, tais como ferro $\left(\mathrm{FeCl}_{3} \cdot \mathrm{H}_{2} \mathrm{O}\right)$; manganês $\left(\mathrm{MnSO}_{4} \cdot \mathrm{H}_{2} \mathrm{O}\right)$; zinco $(\mathrm{ZnO}$ ou $\left.\mathrm{ZnSO}_{4} \cdot 7 \mathrm{H}_{2} 0\right)$; molibdênio $\left(\mathrm{NaMoO}_{4} \cdot \mathrm{H}_{2} \mathrm{O}\right)$; iodo (KI) e cobre $\left(\mathrm{CuSO}_{4} .5 \mathrm{H}_{2} \mathrm{O}\right)$, cujo intervalo de utilização está entre 0,5 a 13,0 mg por $100 \mathrm{~mL}$ (REED, 1983).

Castro (1993) considera que o crescimento total do microrganismo depende da natureza dos fatores 
limitantes e que o pH é um dos mais importantes, juntamente com a exaustão dos nutrientes e do acúmulo de produtos tóxicos. $\mathrm{O} \mathrm{pH}$ dentro de certos limites $(6,5$ a 8,0$)$ tem pouca influência na taxa de crescimento, mas pode influenciar o número total de bactérias. No entanto, valores de $\mathrm{pH}$ extremamente baixos (menores que 4,5) podem levar o microrganismo rapidamente à morte.

Para cada bactéria há uma temperatura ótima de crescimento que pode ser diferente da temperatura ótima de produção de polissacarídeo, mesmo quando a bactéria se encontra em um meio com os nutrientes adequados (CONGREGADO et al., 1985; MANRESA; ESPUNY; GUINEA, 1987).

Durante a fermentação, a fonte de carbono é convertida pela célula microbiana em biopolímero sob certos parâmetros fixos $(\mathrm{pH}$, temperatura, tempo de incubação, etc). Concentrações limitantes de alguns nutrientes e excesso de carboidrato geralmente favorecem a produção de polissacarídeos (SUTHERLAND, 1979).

\section{Produção de Levana}

A levana pode ser sintetizada por vários grupos de bactérias, entre elas, Bacillus subtilis (CHAMBERT; TREBOUL; DEDONDER, 1974) e Zymomonas mobilis (YANASE et al., 1992), através de meio fermentativo à base de sacarose, extrato de levedura e sais minerais (VIIKARI, 1988).

A enzima responsável pela formação de levana é a levanasacarase, encontrada em diferentes microrganismos, que se cultivados em condições adequadas de fermentação podem ter potencial para produzir levana em escala industrial (MATOON et al., 1955; HESTRIN; FEINGOLD; AVIGAD, 1956; AVIGAD, 1968; YAMAMOTO et al., 1985; LIZUKA et al., 1991; KOJIMA et al., 1993).

Hernandez et al. (1995) observaram que a atividade da levanasacarase está envolvida em processos variados: sobrevivência de bactérias no solo (Bacillus subtilis), fitopatogêneses (Erwinia e
Pseudomonas ssp) ou simbiose de plantas interagindo com bactérias (Bacillus polymyxa).

Quando a bactéria Bacillus subtilis é incubada no meio contendo sacarose, a enzima levanasacarase catalisa a formação de levana de alto peso molecular (DEDONDER; NOBLESSE, 1953; COTÉ; AHLGREN, 1993). Entretanto, poucas levanasacarases mostraram-se ativas em altas temperaturas. Entre estas, a obtida de Zymomonas mobilis (SANGILIYANDI; GUNASEKARAN, 1998), Ranhnella aquatilis JCM-1683 (OHTSUKA et al., 1992) e Pseudomonas syringae (HETTWER; GROSS; RUDOLPH, 1995) foram consideradas como termoativas.

Segundo Ammar et al. (2002), a enzima fructosiltransferase ou levanasacarase $(2,6-\beta$-Dfrutana-6- $\beta$-D-frutosiltransferase, E.C. 2.4.1.10) catalisa a seguinte reação:

sacarose $+(2,6-\beta-\mathrm{D} \text { - frutosil })_{n}$

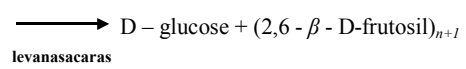

$\mathrm{O}$ pH ótimo para a atividade da enzima levanasacarase é de 6,5. Em culturas contendo sacarose, pode-se utilizar $\mathrm{pH}$ com valores menores para a produção adequada de levana pela mesma enzima.

\section{Produção de Levana por Zymomonas mobilis}

$\mathrm{O}$ interesse por Zymomonas mobilis tem sido crescente, pois é uma alternativa promissora não só para a produção de etanol como também para a levana (SWINGS; DE LEY, 1977; ROGERS et al., 1982).

Zymomonas mobilis é uma bactéria Gramnegativa, anaeróbia facultativa, e quando cultivada em meio rico em sacarose promove à conversão do dissacarídeo em glucose e frutose. É também capaz de produzir outros metabólitos em altas concentrações sob condições de cultura adequadas, como por exemplo, sorbitol, gluconato e frutooligossacarídeos (JOHNS; GREENFIELD; DOELLE, 1991; BEKERS et al., 1993).

Em 1986, Viikari e Gisler pesquisaram a produção de bioprodutos por diferentes linhagens de Zymomonas mobilis durante a fermentação de sacarose. Foram comparadas oito linhagens de 
acordo com a hidrólise de sacarose e a conseqüente formação de etanol, levana e sorbitol. Baixa proporção de hidrólise de sacarose foi associada com a formação de levana e a alta proporção de hidrólise de sacarose com a formação de sorbitol.

Rodríguez e Calliere (1986) isolaram diferentes linhagens de Zymomonas mobilis capazes de produzir levana em alta concentração. Algumas dessas linhagens foram cultivadas sob condições de culturas contínuas ou através de batelada.

Calazans et al. (1989 apud DOELLE, 1993) observaram que a concentração de levana produzida por Zymomonas mobilis em condições de cultura por batelada contendo $\left(\mathrm{NH}_{4}\right)_{2} \mathrm{SO}_{4}$ como fonte de nitrogênio foi $12,7 \%$, enquanto que, Bekers et al. (1990), utilizando uma linhagem de Zymomonas mobilis denominada 113 "S", observaram que esta pôde produzir aproximadamente 30-50 g/L de levana em condições de fermentação por batelada ou contínua.

Em 1991, Carlos realizou ensaios usando um mosto de fermentação a base de sacarose, em processo por batelada, utilizando seis linhagens de Zymomonas mobilis. A linhagem melhor produtora apresentou maior capacidade de conversão de substrato em levana, formando 3,78 g/L (expressa como frutose). Este autor utilizou a técnica de otimização "simplex ortogonal", o que possibilitou a obtenção da melhor composição do meio (concentração máxima: em 30 horas, 4,49 g/L, expressa como frutose) produção de etanol (concentração máxima: em 42 horas, 40,35 g/L) e crescimento de biomassa celular. A velocidade máxima de crescimento celular foi de $0,224 \mathrm{~h}^{-1}$.

Segundo Doelle et al. (1993), a temperatura e o pH influenciam diretamente a produção de levana por Zymomonas mobilis e Bacillus subtilis. Temperaturas baixas aumentaram o rendimento de produção de levana e temperaturas em torno de $34^{\circ} \mathrm{C}$ inibiram todas as linhagens de Zymomonas mobilis. $\mathrm{O}$ pH ótimo para a produção de levana foi de aproximadamente 5,0. Em pH 6,5, foi observado que houve redução da produção, porém ocorreu a hidrólise de sacarose.

Jerez (1993) conduziu um estudo sobre métodos e condições de fermentação de melaço de cana-deaçúcar por Zymomonas mobilis CP4 e seu efeito sobre os parâmetros cinéticos de fermentação. Avaliou o efeito da temperatura, controle de $\mathrm{pH}$ e efeito de íons $\mathrm{Ca}^{++}, \mathrm{K}^{+}, \mathrm{Cl}^{-}$e $\mathrm{Mg}^{++}$em meio de fermentação com sacarose. Em melaço de cana-deaçúcar, foram estudados os efeitos da clarificação e suplementação com nutrientes. Determinaram-se os parâmetros cinéticos de fermentação do melaço em processo descontínuo, descontínuo alimentado e contínuo em escala de laboratório, descontínuo e descontínuo alimentado em escala piloto. Os tratamentos de clarificação do melaço removeram $\mathrm{Ca}^{++}$e $\mathrm{K}^{+}$, mas não aumentaram o rendimento da fermentação. Foi observado que $\mathrm{Ca}^{++}, \mathrm{K}^{+}$e $\mathrm{Cl}^{-}$são inibidores do crescimento e fermentação de Zymomonas mobilis $\mathrm{CP} 4$, mas $\mathrm{o}^{\mathrm{Mg}^{++}}$não apresentou efeito inibitório em nenhuma das condições estudadas. Portanto, é necessária a suplementação do melaço para aumentar os rendimentos da produção de levana.

Silva (1996) realizou experimentos para estudar a influência do $\mathrm{pH}$ sobre a formação de levana por Zymomonas mobilis ZAG-12 em meios à base de sacarose. Para o controle do $\mathrm{pH}$ foram utilizadas soluções alcalinas e ácidas e, também, soluções tampões. Cada experimento foi realizado em diferentes valores iniciais de $\mathrm{pH}$, tanto nos ensaios com controle como sem controle do $\mathrm{pH}$. O acompanhamento das fermentações foi feito pela retirada de amostras, a intervalos de tempo determinados, para as dosagens de biomassa celular, açúcares totais, $\mathrm{pH}$, levana precipitável e etanol. A análise destes demonstraram que a linhagem cresce bem numa faixa de $\mathrm{pH}$ entre 4,5 e 6,0. O controle do $\mathrm{pH}$ ao longo da fermentação mostrou uma menor quantidade de levana precipitável em comparação com as fermentações realizadas sem o controle do $\mathrm{pH}$ ( $\mathrm{pH}$ ente 4,5 e 5,0). O rendimento em levana formada foi maior nas primeiras 24 horas de 
fermentação. A faixa de pH inicial entre 5,5 e 6,0, nas fermentações com controle de $\mathrm{pH}$ e naquelas contendo solução tampão, ocasionou uma maior eficiência bioquímica de produção de etanol e pequena formação de levana precipitável, em comparação às fermentações sem controle de $\mathrm{pH}$.

Estudos realizados por Vigants et al. (1998) verificaram que o efeito de sais minerais e da osmolaridade pode influenciar a síntese de levana. $\mathrm{O}$ efeito de $\mathrm{KCl}$ e $\mathrm{NaCl}$ não só estimulou a produção de etanol como também a de levana, já que teve ação direta sobre a enzima levanasacarase responsável pela produção de ambos os produtos.

Vinhas (1999) realizou um trabalho que teve como objetivos selecionar dentre duas linhagens de Zymomonas mobilis, ZAG-12 e ZAP, a melhor produtora de levana, verificar a produção com e sem agitação, influência da concentração inicial de sacarose sobre o rendimento final de fermentação, fracionar as levanas produzidas, determinar o peso molecular das levanas e desenvolver o diagrama ternário da mistura levana - água - etanol. As levanas foram produzidas em meio à base de sacarose suplementado com extrato de levedura e sais minerais. A produção em batelada foi realizada em frascos com e sem agitação, nas concentrações iniciais de sacarose de 200 e $250 \mathrm{~g} / \mathrm{L}$, à temperatura de $25^{\circ} \mathrm{C}$ por 72 horas de processo. $\mathrm{O}$ acompanhamento das fermentações consistiu na retirada de amostras, a intervalos de tempo determinados, para dosagens de biomassa celular, açúcares totais, levana e verificação do $\mathrm{pH}$. O fracionamento foi realizado pelo método de precipitação fracionada utilizando o etanol como não solvente e a determinação dos pesos moleculares das levanas produzidas foram realizadas pelo método de cromatografia de permeação em gel. A construção do diagrama ternário foi feita utilizando-se o método de titulação turbidimétrica. Os resultados mostraram que a melhor produtora de levana foi a Zymomonas mobilis linhagem ZAG-12, e que as melhores condições de produção foram concentração de sacarose inicial de $200 \mathrm{~g} / \mathrm{L}$, sem agitação. O fracionamento das levanas por precipitação com etanol possibilitou a construção de um histograma de distribuição das frações, indicando que as levanas produzidas apresentam diferentes faixas de peso molecular. A curva de solubilidade mostrou que é possível se obter o equilíbrio dos três componentes numa mistura, e evidenciou as áreas onde a mistura é homogênea (área acima da curva) ou heterogênea (área abaixo da curva).

Muro et al. (2000) investigaram a produção de levana usando linhagens de Zymomonas mobilis em diferentes condições de cultivo, obtendo elevada produção de levana $\left(41 \mathrm{~g} \mathrm{~L}^{-1}\right)$ com uma linhagem mutante HL 29 em meio de cultura contendo $200 \mathrm{~g}$ de sacarose $\mathrm{L}^{-1}$ e $0,5 \mathrm{~g}$ de $\left(\mathrm{NH}_{4}\right)_{2} \mathrm{SO}_{4} \mathrm{~L}^{-1}$ estocados a $7^{\circ} \mathrm{C}$ por 29 dias. Esta foi a primeira pesquisa que descreveu a síntese de levana por Zymomonas mobilis a $7^{\circ} \mathrm{C}$.

Bekers et al. (2000) pesquisaram o efeito de altas concentrações de sal durante a fermentação de sacarose (10\%) por Zymomonas mobilis. Foi verificado que a concentração de $0,6 \mathrm{M}$ de uma solução de $\mathrm{NaCl}$ levou a um aumento da síntese de levana. A produção de sorbitol aumentou na presença de solução de $\mathrm{NaCl} 0,16 \mathrm{M}$, porém foi inibida em concentrações maiores do sal.

Wendt (2001) pesquisou uma linhagem de Zymomonas mobilis mutante obtida através do tratamento da cepa natural com NTG (N - metil N'nitro N'nitroso guanidina). Os resultados mostraram que esta mutante pode produzir até $30 \mathrm{~g} /$ L de levana e que a concentração de extrato de levedura pode influenciar a síntese da levana.

Borsari, Celligoi e Buzato (2003) estudaram a produção de levana por Zymomonas mobilis em fermentação descontínua alimentada. O microrganismo foi cultivado em meio de sacarose acrescido de caldo de cana de açúcar $(200 \mathrm{~g} / \mathrm{L}), \mathrm{pH}$ $5,25^{\circ} \mathrm{C}$, por 20 horas. A produção de levana e a biomassa foram 14,83 $\mathrm{g} / \mathrm{L}$ e 1,56 $\mathrm{g} / \mathrm{L}$ no processo descontínuo e $10,3 \mathrm{~g} / \mathrm{L}$ e $1,91 \mathrm{~g} / \mathrm{L}$ no descontínuo alimentado com um consumo de açúcares de 78,21 $\mathrm{g} / \mathrm{L}$ e $163,55 \mathrm{~g} / \mathrm{L}$ respectivamente. Segundo os mesmos autores, estes resultados demonstraram que 
apesar de ter ocorrido um maior consumo de açúcares no processo descontínuo alimentado, não houve diferenças estatisticamente significativas na produção de levana nos processos estudados.

Tano e Buzato (2003) avaliaram a produção de etanol em caldo de cana fermentado por Zymomonas mobilis com alta concentração de açúcar inicial na presença e na ausência de etanol inicial. Constataram que a presença de etanol inicial não teve efeito significante para a produção de levana e no coeficiente de produtividade em biomassa ( $\mathrm{g}$ biomassa / g açúcar consumido).

\section{Produção de Levana por Outras Bactérias}

Apesar de vários microrganismos produzirem exopolissacarídeos, poucas pesquisas têm sido realizadas com espécies de Bacillus para a produção de biopolímeros (DEDONDER, 1966; HAN; CLARKE, 1990). Entretanto, alguns pesquisadores estão voltando sua atenção para Bacillus polymyxa pelo fato dele transformar $40 \%$ da fonte de carbono utilizada em levana (HAN, 1989).

Tkachenko e Sevryugina (1989) pesquisaram a biossíntese de levana por Bacillus polymyxa isolado de ágar industrial. Eles observaram que o $\mathrm{pH}$ neutro foi ótimo para a produção do polissacarídeo induzindo a produção da levanasacarase pelo microrganismo. As fontes de carbono sacarose e ramnose, utilizadas para o crescimento do microrganismo, serviram de substratos para a enzima realizar a hidrólise de sacarose levando a formação de levana.

Han (1989) utilizou a sacarose, caldo de cana e melaços de beterraba como fontes de carbono e constatou que o Bacillus polymyxa converteu cerca de $46 \%$ da metade de frutose da molécula de sacarose em levana. Além de que, segundo Han e Watson (1992), o caldo de cana e o melaço de beterraba, após filtração em gel, tornavam-se bons substratos para a produção deste polímero.

Garcia-Cruz (1997) testou diferentes concentrações $(1,2,3$, 4 e 5\%) de glucose, sacarose, frutose, lactose e manitol sobre os parâmetros de fermentação durante a produção de levana por Bacillus polymyxa e observou o aumento da massa celular a medida que a concentração da fonte de carbono aumentou. Com relação à produção de levana, observou que, embora se aumentasse a concentração da fonte de carbono, não ocorria qualquer acréscimo na produção. A melhor concentração para a produção de levana foi $1 \%$ e, em termos gerais, o manitol demonstrou ser a melhor fonte de carbono para sua produção. Tais resultados estão de acordo com os obtidos por Tkachenko e Sevryugina (1989), uma vez que estes pesquisadores constataram, durante a biossíntese de levana por Bacillus polymyxa, que o manitol promoveu um aumento da biomassa e estimulou a produção de levana.

\section{Referência}

AMMAR, Y. B.; MATSUBARA, T.; ITO, K.; ILZUKA, M.; LIMPASENI, T.; PONGSAWASDI, P.; MINAMIURA, $\mathrm{N}$. Characterization of a thermostable levansucrase from Bacillus sp. TH4-2 capable of producing high molecular weight levan at high temperature. Journal of Biotechnology, Amsterdam, v. 99, n. 2, p. 111-119, 2002.

AVIGAD, G. Levans. In: BIKALES, N. M.; CONRAD, J. (Ed.). Encyclopedia of Polymer Science and Technology. New York: John Wiley \& Sons, 1968. v. 8, p. 711-718.

BEKERS, M. J.; SHVINKA, J. E.; PANKOVA, L. M.; LAIVENIEKS, M. G.; MEZHBARDE, I. N. A simultaneous sucrose bioconversion into ethanol and levan by Zymomonas mobilis. Applied Biochemistry and Biotechnology, Totowa, v. 24, p. 265-274, 1990.

BEKERS, M.; SHVINKA, J.; RAIPULIS, J.; LAIVENIEKS, M.; PANKOVA, L.; MEZBARDE, I. Strain Zymomonas mobilis - The producer of levan. Latvian Patent, Nr. 5909. 1993.

BEKERS, M.; VIGANTS, A.; LAUKEVICS, J.; TOMA, M.; RAPOPORTS, A.; ZIKMANIS, P. The effect of osmoinduced stress on product formation by Zymomonas mobilis on sucrose. International Journal of Food Microbiology, Amsterdam, v. 55, p. 147-150, 2000.

BORSARI, R. R. J.; CELLIGOI, M. A. P. C.; BUZATO, J. B. Produção de Levana por Zymomonas mobilis em fermentação descontínua alimentada. In: CONGRESSO DA SOCIEDADE BRASILEIRA DE MICROBIOLOGIA, 22. 2003, Florianópolis. Anais Florianópolis, 2003. 
BUENO, S. M. Isolamento e caracterização de bactérias selvagens produtoras de polissacarídeos obtidas de amostras de solo da estação ecológica de São José do Rio Preto - SP. 2001, 161f. Dissertação (Mestrado em Engenharia de Alimentos) - Instituto de Biociências, Letras e Ciências Exatas. Universidade Estadual Paulista, São José do Rio Preto, 2001.

BUENO, S. M.; GARCIA-CRUZ, C. H. The influence of fermentation time and the presence of salts in the rheology of the fermentation broth of a polysaccharide-producing bacteria free of soil. Journal of Food Engineering, Oxford, v. 50, n. 1, p. 41-46, 2001.

CALAZANS, G. M. T.; LOPES, C. E.; LIMA, R. M. O. C.; FRANCA, F. P. Antitumor activity of levans produced by Zymomonas mobilis strains. Biotechnology Letters, London, v. 19, n. 1, p. 19-21, 1997.

CARLOS, T. F. Produção de levana pela bactéria Zymomonas mobilis em mosto a base de sacarose. 1991, 74f. Dissertação (Mestrado em Ciências Farmacêuticas) Universidade Federal de Pernambuco. Recife, 1991.

CASTRO, A. F. P. Curva de crescimento bacteriano e noções sobre bacteriologia quantitativa. Campinas: UNICAMP, 1993. 25p. Apostila de TC1.

CHA, J.; PARK, N. H.; YANG, S. J.; LEE, T. H. Molecular and enzymatic characterization of a levan frutotransferase from Mycrobacterium sp AL-210. Journal of Biotechnology, Amsterdam, v. 91, n. 1, p. 49-61, 2001.

CHAMBERT R.; TREBOUL, G.; DEDONDER, R. Kinetic studies of levansucrase of Bacillus subtilis. European Journal Biochemistry, New York, v. 41, n. 2, p. 285-300, 1974.

COLTRO, A. L. Produção e determinação da composição dos exopolissacarídeos produzidos por bactérias isoladas da rizosfera. 2003, 104f. Dissertação (Mestrado em Engenharia de Alimentos) - Instituto de Biociências, Letras e Ciências Exatas. Universidade Estadual Paulista, São José do Rio Preto, 2003.

CONGREGADO, F.; ESTAÑOL, I.; ESPUNY, M. J.; FUSTÉ, M. C.; MANRESA, M. A.; MARQUEZ, A. M.; GUINÉA, J.; SIMON-PUJOL, M. D. Preliminary studies on the production and composition of the extracellular polysaccharide synthesized by Pseudomonas sp EPS5029. Biotechnology Letters, London, v. 7, n. 12, p. 883$888,1985$.

COTÉ, G. L.; AHLGREN, J. A. Metabolism in microorganisms. Part I. Levan and levansucrase. In: SUZUKI, N.; CHATTERTON, N. J. (Ed.). Science and Technology of Fructans. Boca Raton: CRS Press, 1993. p. 142-168.
DEDONDER, R.; NOBLESSE, C. Evidence for intermediate products containing glucose in the synthesis of levan by Bacillus subtilis. Annales de L Institut Pasteur, Paris, v. 85, n. 3, p. 356-364, 1953.

DEDONDER, R. Levansucrase from Bacillus subtilis. Methods in Enzymology, New York, v. 8, p. 500-505, 1966.

DOELLE, H. W.; KIRK, L.; CRITTENDEN, R.; TOH, H.; DOELLE, M. B. Zymomonas mobilis - science and industrial application. Critical Reviews in Biotechnology, Boca Raton, v. 13, n. 1, p. 57-98, 1993.

EUZENAT, O.; GUIBERT, A.; COMBES, D. Production of fructo-oligosaccharides by levansucrase from Bacillus subtilis C4. Process Biochemistry, Oxford, v. 32, n. 3, p. 237-243, 1997.

FARIA, L. H. G. B. Caracterização taxonômica e produção de polissacarídeos utilizando bactérias isoladas de amostras de solo. 2002, 162f. Dissertação (Mestrado em Engenharia de Alimentos) - Instituto de Biociências, Letras e Ciências Exatas. Universidade Estadual Paulista, São José do Rio Preto, 2002.

FOOD \& DRUG ADMINISTRATION. Food additives permitted in food for human consumption: Xanthan gum. Federal Register, Washington, v. 34, n. 53, pt 121, p. 5376, 1969.

GANDHI, H. P.; RAY, R. M.; PATEL, R. M. Exopolymer production by Bacillus species. Carbohydrate Polymers, Oxford, v. 34, n. 4, p. 323-327, 1997.

GARCIA-CRUZ, C. H. Produção de polissacarídeos bacterianos. 1997, 63f. Tese (Livre Docencia) - Instituto de Biociências, Letras e Ciências Exatas. Universidade Estadual Paulista, São José do Rio Preto, 1997.

GUNASEKARAN, P.; RAJ., K. C. Ethanol fermentation technology - Zymomonas mobilis. Current Science, Bangalore, v. 77, n. 1, p. 56-68, 1999.

HAN, Y. W. Levan production by Bacillus polymyxa. Journal of Industrial Microbiology, Hampshire, v. 4, n. 6, p. 447-451, 1989.

HAN, Y. W.; CLARKE, M. A. Production and characterization of microbial levan. Journal of Agricultural and Food Chemistry, Washington, v. 38, n. 2, p. 393-396, 1990.

HAN, Y. W.; WATSON, M. A. Production of microbial levan from sucrose, sugarcane juice and beet molasses. Journal of Industrial Microbiology, New Orleans, v. 9, p. 257-260, 1992.

HARTMEIER, W.; REISS, M.; HEIDEL, M.; MARX, S. Biochemical and economical aspects of levan synthesis by Zymomonas mobilis. Biocatalysis, Berks, v. 10, p. 131136, 1994. 
HERNANDEZ, L.; ARRIETA, J.; MENENDEZ, C.; VAZQUEZ, R.; COEGO, A.; SUAREZ, V.; SELMAN, G.; PETIT-GLATRON, M. F.; CHAMBERT, R. Isolation and enzymic properties of levansucrase secreted by Acetobacter diazotrophicus SRT4, a bacterium associated with sugar cane. Biochemical Journal, London, v. 309, p. 113-118, 1995.

HESTRIN, S.; FEINGOLD, D. S.; AVIGAD, G. The mechanism of polysaccharide production from sucrose. 3. Donor-acceptor specificity of levansucrase from Aerobacter levanicum. Biochemical Journal, London, v. 64, n. 2, p. 340-351, 1956.

HETTWER, U.; GROSS, M.; RUDOLPH, K. Purification and characterization of an extracellular levansucrase from Pseudomonas syringae pv. phaseolicola. Journal of Bacteriology, Washington, v. 177, n. 10, p. 2834-2839, 1995.

JEREZ, M. C. D. Estudo comparativo de diferentes métodos e condições de fermentação de melaço de canade-açúcar por Zymomonas mobilis. 1993. 108f. Dissertação (Doutorado em Ciência de Alimentos) - Universidade Estadual de Campinas, Campinas, 1993.

JOHNS, M. R.; GREENFIELD, P. F.; DOELLE, H. W. Byproducts from Zymomonas mobilis. Advances In Biochemical Engineering/Biotechnology, Berlin, v. 44, p. 97-121, 1991.

KEITH, J.; WILEY, B.; BALL, D.; ARCIDIACONO, S.; ZORFASS, D.; MAYER, J.; KAPLAN, D. Continuous culture system for production of biopolymer levan using Erwinia-Herbicola. Biotechnology and Bioengineering, New York, v. 38, n. 5, p. 557-560, 1991.

KOJIMA, I.; SAITO, T.; IIZUKA, M.; MINAMIURA, M.; ONO, S. Characterization of levan produced by Serratia sp. Journal of Fermentation and Bioengineering, Osaka, v. 75, n. 1, p. 9-12, 1993.

LEIBOVICI, J.; BORITA, A.; SANDBANK, U.; WOLMAN, $\mathrm{M}$. Role of macrophages and polymorphs in the levaninduced inhibition of Lewis lung carcinoma in C 57BL mice. British Journal of Cancer, Edinburgh, v. 40, n. 4, p. 597$607,1979$.

LEIBOVICI, J.; STARK, Y. Increase in cell permeability to a cytotoxic agent by the polysaccharide levan. Cellular and Molecular Biology, Noisy Le Grand, v. 31, n. 5, p. 337-341, 1985.

LIZUKA, M.; TANAKA, T.; YAMAMOTO, S.; YONEDA, Y.; ITOKAWA, S.; HIYAMA, M.; ITO, K.; FURUICHI, K.; MINAMIURA, N.; YAMAMOTO, T. Synthesis of fructan and oligosaccharides by microbial and plant fructosyltransferase. Denpun Kagaku, Tokyo, v. 38, p. 217-222, 1991.
LOPES, L.; ANDRADE, C. T.; MANO, E. B. O valor das gomas para a indústria. Ciência Hoje, São Paulo, v. 12, p. 65-67, 1991.

MANRESA, A.; ESPUNY, M. J.; GUINEA, J.; COMELLES, F. Characterization and production of a new extracellular polymer from Pseudomonas sp GPS-910. Applied Microbiology and Biotechnology, New York, v. 26, n. 4, p. 347-351, 1987.

MAYS, T. D.; DALLY, E. L. Microbial production of polyfrutose. Patent U. S., n.4, p.769-254, 1988.

MATOON, J. R.; HOLMLUND, C. E.; SCHEPARTZ, S. A.; VAVRA, J. J.; JOHNSON, M. J. Bacterial levans of intermediate molecular weight. Applied Microbiology, Washington, v. 3, n. 6, p. 321-333, 1955.

MELO, I. S.; AZEVEDO, J. L. Ecologia microbiana. Jaguariúna: Embrapa, 1998. 488p.

MURO, A. C.; RODRIGUEZ, E.; ABATE, C. M.; SIÑERIZ, F. Levan production using mutant strains of Zymomonas mobilis in different culture conditions. Biotechnology Letters, Netherlands, v. 22, n. 20, p. 1639-1642, 2000.

OHTSUKA, K.; HINO, S.; FUKUSHIMA, T.; OZAWA, O.; KANEMATSU, T.; UCHIDA, T. Characterization of levansucrase from Rahnella aqualitis JMC-1683. Bioscience Biotechnology and Biochemistry, Tokyo, v. 56, n. 9, p. 1373-1377, 1992.

PACE, G. W.; RIGHELATO, R. C. Production of extracellular microbial polysaccharides. Advances in Biochemical Engineering, New York, v. 15, p. 41-70, 1980.

PSZCZOLA, D. E. Gellan gum wins IFT's food technology industrial achievement award. Food Technology, Chicago, v. 47, p. 94-96, 1993.

QUEIROZ, G. M. Isolamento e caracterização de bactérias produtoras de polissacarídeos obtidas de amostra da rizosfera de plantas. 2001. 116f. Dissertação (Mestrado em Engenharia de Alimentos) - Instituto de Biociências, Letras e Ciências Exatas. Universidade Estadual Paulista, São José do Rio Preto, 2001.

REED, G. Microbial biomass. Single cell protein and other microbial products. In: REED, G. Prescott \& dunn's industrial microbiology. Westport: AVI, 1983. p. 543-557.

REISS, M.; HARTMEIER, W. Levan production with a flocculent strain of Zymomonas mobilis. Food Biotechnology, New York, v. 4, p. 69-75, 1990.

RODRÍGUEZ, E.; CALLIERI, D. A. S. High-yield conversion of sucrose into ethanol by a flocculant Zymomonas sp. Isolated from sugarcane juice. Biotechnology Letters, London, v. 8, n. 10, p. 745-748, 1986.

ROGERS, P.; LEE, K.; SKOTNICHI, M.; TRIBE, D. Ethanol production by Zymomonas mobilis. Advances in Biochemical Engineering, New York, v. 23, p. 37-83, 1982. 
SANDFORD, P. A. Potential important microbial gums. In: GLICKSMAN, M. Food hydrocolloids. Boca Raton: C. R. C. Press, 1982. v. 1, p. 168-199.

SANDFORD, P. A.; COTTRELL, I. W.; PETTITT, D. J. Microbial polysaccharides: new products and their commercial applications. Pure and Applied Chemistry, Oxfodr, v. 56, n. 7, p. 879-892, 1984.

SANGILIYANDI, G.; GUNASEKARAN, P. A simple method for purification of thermostable levansucrase of Zymomonas mobilis from recombinant Escherichia coli. Journal of Microbiological Methods, Amsterdam, v. 33, n. 2, p. 153-156, 1998.

SILVA, M. C. P. Influência do pH sobre a produção de levana pela Zymomonas mobilis ZAG-12 em meio à base de sacarose. 1996, 96f. Dissertação (Mestrado em Ciências Farmacêuticas) - Universidade Federal de Pernambuco, Recife,1996.

SUTHERLAND, I. W. Bacterial Exopolysaccharides. Advances in Microbial Physiology, London, v. 8, p. 143213, 1972.

SUTHERLAND, I. W. Enhancement of polysaccharides viscosity by mutagenesis. Journal of Applied Biochemistry, San Diego, v. 1, p. 60-70, 1979.

SUTHERLAND, I. W. Biosynthesis of extracellular polysaccharides (exopolysaccharides). In: WHISTLER, R. L.; BEMILLER, J. N. Industrial gums: polysaccharides and their derivatives. 3. ed. San Diego: Academic Press, 1993. p. 69-85.

SUTHERLAND, I. W. Polysaccharases for microbial exopolysaccharides. Carbohydrate Polymers, Barking, v. 38, p. 319-328, 1999.

SUTHERLAND, I. W. Microbial polysaccharides from Gram-negative bacteria. International Dairy Journal, Oxford, v. 11, n. 9, p. 663-674, 2001.

SWINGS, J.; DELEY, J. Biology of Zymomonas. Bacteriological Reviews, Washington, v. 41, n. 1, p. 1-46, 1977.

TAKO, M., NAKAMURA, S. Rheological properties of $\mathrm{Ca}^{+2}$ salt of xanthan in aqueous media. Agricultural and Biological Chemistry, Tokyo, v. 51, n. 11, p. 2919-2923, 1987.

TANO, M. S.; BUZATO, J. B. Effect of the presence of initial ethanol on ethanol production in sugar cane juice fermented by Zymomonas mobilis. Brazilian Journal of Microbiology, Sao Paulo, v. 34, p. 242-244, 2003.

TAPER, H. S.; DELZENNE, N. M.; ROBERFROID, M. B. Growth inhibition of transplantable mouse tumors by nondigestible carbohydrates. International Journal of Cancer, New York, v. 71, n. 6, p. 1109-1112, 1997.

TKACHENKO, A. A.; SEVRYUGINA, T. V. Biosynthesis of Levan by Bacillus polymyxa. Microbiology, New York, v. 58, n. 3, p. 457-461, 1989.
UEDA, M.; SASHIDA, R.; MORIMOTO, Y.; OHKISHI, H. Purification of inulin fructotransferase (DFA I-producing) from Arthrobacter sp. MCI2493 and production of DFA I from inulin by the enzyme. Bioscience Biotechnology and Biochemistry, Tokyo, v. 58, n. 3, p. 574-575, 1994.

VIGANTS, A.; KRUCE, R.; BEKERS, M.;ZIKMANIS, P. Response of Zymomonas mobilis levansucrase activity to sodium chloride addition. Biotechnology Letters, Netherlands, v. 20, n. 11, p. 1017-1019, 1998.

VIIKARI, L.; GISLER, R. By-products in the fermentation of sucrose by different Zymomonas strains. Applied Microbiology and Biotechnology, New York, v. 23, p. 240244, 1986.

VIIKARI, L. Carbohydrate metabolism in Zymomonas. Critical Reviews in Biotechnology, Boca Raton, v. 7, p. 236-261, 1988.

VINA, I.; KARSAKEVICHA, A.; TOMA, M.; BEKERS, M. Polysaccharide levan and its derivatives as wide spectrum immunomudolators: biosynthesis, obtaining and investigation. In: EUROPEAN CONGRESS ON BIOTECHNOLOGY, 8., 1997, Budapest. Abstracts...Budapest, 1997. p. 105-106.

VINHAS, G. M. Estudo da produção e do fracionamento de levanas produzidas por Zymomonas mobilis. 1999, 66f. Dissertação (Mestrado em Biotecnologia de produtos bioativos) - Universidade Federal de Pernambuco, Recife, 1999.

WENDT, R. Estudos da produção de levana através de Zymomonas mobilis. 2001. 100f. Dissertação (Mestrado em Ciências de Alimentos) - Universidade Estadual de Campinas, Campinas, 2001.

YAMAMOTO, S.; IIZUKA, M.; TANAKA, T.; YAMAMOTO, T. The mode of synthesis of levan by Bacillus-subtilis levansucrase. Agricultural and Biological Chemistry, Tokyo, v. 49, n. 2, p. 343-349, 1985.

YAMAMOTO, Y.; TAKAHASHI, Y.; KAWANO, M.; IIZUKA, M.; MATSUMOTO, T.; SAEKI, S.; YAMAGUCHI, H. In vitro digestibility and fermentability of levan and its hypocholesterolemic effect in rats. Journal of Nutritional Biochemistry, New York, v. 10, n. 1, p. 13-18, 1999.

YANASE, H.; IWATA, M.; NAKAHIGASHI, R.; KITA, K.; KATO, N.; TONOMURA, K. Purification, crystallization and properties of the extracellular levansucrase from Zymomonas mobilis. Bioscience Biotechnology and Biochemistry, Tokyo, v. 56, n. 8, p. 1335-1337, 1992.

YUN, J. W. Fructooligosaccharides - Occurrence, preparation and application. Enzyme and Microbial Technology, Woburn, v. 19, n. 2, p. 107-117, 1996. 